TAPROBANICA, ISSN 1800-427X. August, 2014. Vol. 06, No. 02: pp. 83-89, pls. 4-6.

(C) Research Center for Climate Change, University of Indonesia, Depok, Indonesia

\& Taprobanica Private Limited, Homagama, Sri Lanka

http://www.sljol.info/index.php/tapro

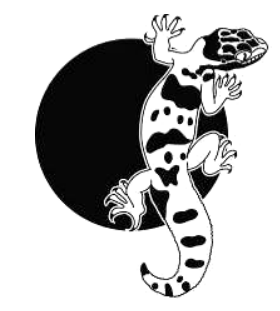

\title{
TEMPORAL DIOECISM, MELITTOPHILY AND ANEMOCHORY OF Wendlandia glabrata (RUBIACEAE)
}

\author{
Section Editor: James L. Reveal \\ Submitted: 12 March 2014, Accepted: 18 March 2014
}

\author{
A. J. Solomon Raju ${ }^{1,2}$ and K. Venkata Ramana ${ }^{1}$
}

${ }^{1}$ Department of Environmental Sciences, Andhra University, Visakhapatnam 530003, India
${ }^{2}$ E-mail: ajsraju@yahoo.com

\begin{abstract}
Wendlandia glabrata is a massive bloomer during February-March. Floral characteristics such as diurnal anthesis, white coloured, odorless, tubular flowers with deep seated sucrose-rich nectar conform to psychophily. Nectar is a source of essential and non-essential amino acids for butterflies, inconsistent foragers due to nectar traces in open flowers. This suggests a breakdown of psychophilous pollination. Honey bees consistently collect only pollen. Flies are also inconsistent nectar foragers. Therefore, W. glabrata with psychophilous pollination syndrome is actually melittophilous, and the flowers exhibit Secondary Pollen Presentation (SPP). The flowers are morphologically hermaphroditic but functionally temporally dioecious which promotes outcrossing. Natural fruit and seed set rates are attributed to pollen robbery by honey bees. Anemochory is effective to dispersal of seeds. In situ seedling establishment rate is low due to habit, seasonal herbaceous vegetation, and space limitation. Therefore, we recommend that seedlings be raised in nurseries and transplanted to rebuild populations of W. glabrata.
\end{abstract}

Keywords: psychophily, secondary pollen presentation, tree species, tropical semi-evergreen

\section{Introduction}

The Rubiaceae Juss. are a large family distributed over the temperate and tropical regions of the world. It shows a wide spectrum of floral mechanisms characterized by different types of gynoecium and androecium organization. Despite this diversity, Robbrecht (1988) pointed out the presence of three reproductive strategies common in Rubiaceae: distyly, morphologically characterized by the presence of two inter-compatible floral morphs, which is generally observed in species of Rubioideae Bremek. ex Verdc. (Barrett, 1992); stylar pollen presentation involving protandry and pollen presentation in the style which is generally recorded in Dialypetalanthoideae Reveal (including Ixoroideae Raf.; Nilsson et al. 1990; De Block \& Igerscheim 2001); and the occurrence of unisexual flowers in certain species almost restricted to Rubieae Baill. (including Theligoneae Baill.) and 
Anthospermae Cham. \& Schltdl. (Robbrecht, 1988). In similar lines, Bir Bahadur (1968) documented three types of flower sex in the Rubiaceae - heterostyly, dioecy, and hermaphroditic or gynodioecy. He mentioned that 91 genera with 416 species are dimorphic and heterostylous. Consolaro et al. (2011) reported that Rubiaceae contains the largest number of distylous species in the angiosperms. Puff et al. (1996) reported that Secondary Pollen Presentation (SPP) occurs widely among all subfamilies. These authors have recognized four types of SPP based on the pollen presenting area and receptive surface of style and stigma. In the first type, pollen deposition occurs on the style only and its deposition is strictly on non-receptive surfaces. In the second type, pollen deposition occurs on the style and outside of the stigma lobes; pollen is solely deposited on non-receptive surfaces. In the third type, pollen deposition occurs on the outer surface of the stigma while in the fourth type, it occurs exclusively, largely or partly on the receptive surface of the stigma.

Silberbauer-Gottsberger (1972) stated that many tropical Rubiaceae display floral adaptation suited for Lepidoptera: delicately tubular flowers which are brightly red or orange and pollinated by butterflies (psychophily) or more or less aromatic-scented and whitish in colour that are pollinated by hawk moths or moths (sphingo- and phalaenophily). Wendlandia Bartl. ex DC. (Ixoroideae) is a tropical genus with over 90 species distributed in Asia and one species in Africa (Misra \& Bellwood, 1985). Despite the diversity of species in this genus, there were only two studies that reported on the pollinators of W. uvariifolia Hance and W. tinctoria DC. Xie (2011) reported casually that $W$. uvariifolia with tubular flowers is pollinated by a large spectrum of pollinators including butterflies, flies, and bees in China. Solomon Raju et al. (2012) reported that W. tinctoria with tubular flowers is similarly pollinated by a wide array of pollinators including butterflies, bees, flies, wasps, thrips, and hawk moths. Keeping this information in mind, the present study was contemplated to provide the details of floral biology, sexual system, breeding system, pollen presentation pattern, pollination syndrome, and pollinator guilds of the semi-evergreen dry season blooming tree species, W. glabrata DC. which has a scattered distribution in the Eastern
Ghats of Andhra Pradesh. The work presented in this paper is useful to understand the functional aspects that define the success or failure of sexual systems and pollination syndromes in the context of self-pollination by its species in natural areas.

\section{Materials and Methods}

Field surveys were conducted in northern Eastern Ghats of Andhra Pradesh to locate populations of Wendlandia glabrata. The surveys indicated the occurrence of a single population consisting of 57 scattered individuals at Galikonda, Anantagiri $\left(18^{\circ} 16^{\prime} \mathrm{N}\right.$, $82^{\circ} 59^{\prime} \mathrm{E}$, alt. $2,386 \mathrm{ft}$ ) in an area of two $\mathrm{km}$. This population was used for study during 2012-2013. Twenty five tagged mature buds on ten trees were followed for recording the time of anthesis and anther dehiscence; the mode of anther dehiscence was also noted by using a $10 \mathrm{x}$ hand lens. The details of flower morphology such as flower sex, shape, size, colour, odour, sepals, petals, stamens, and ovary were described. Ten mature but undehisced anthers on five trees were collected and placed in a Petri dish. Later, a single anther was removed and placed on a microscope slide $(75 \times 25 \mathrm{~mm})$ and dabbed with a needle in a drop of lactophenol-aniline-blue. The anther tissue was then observed under a microscope for pollen, if any. When present, the pollen mass was drawn into a band, and the total number of pollen grains counted under a compound microscope (400x). This procedure was followed for counting the number of pollen grains in each anther collected. Based on these counts, the mean number of pollen produced per anther was determined. The mean pollen output per anther was multiplied by the number of anthers of a flower to obtain the mean number of pollen grains per flower. The characteristics of pollen grains were also recorded. Ten fresh flowers were collected from five trees and used to measure nectar sugar concentration with a Hand Sugar Refractometer (Erma, Japan) as per Dafni et al. (2005). Nectar analysis for sugar types was done as per the Paper Chromatography method of Harborne (1973). Nectar analysis for amino acid types was done as per the Paper Chromatography method of Baker \& Baker (1973). The stigma receptivity was tested as per the protocol given by Dafni et al. (2005). Regular observations were made on the insect species visiting flowers for forage. The insects 
were observed on ten trees for eight hours continuously each day for three weeks to determine their foraging behaviour such as mode of approach, landing, probing behaviour, the type of forage they collect, contact with essential organs to result in pollination, and inter-plant foraging activity in terms of crosspollination. Ten specimens of each bee and butterfly species were collected at different times of the day and brought to the laboratory to record the number of pollen grains present on the forehead, body and tongue/proboscis in order to assess their role in pollen transfer and pollination. The specimens were washed first in ethyl alcohol and the contents stained with aniline-blue on a glass slide and observed under a microscope to count the number of pollen grains present. The foragers were observed for ten hours a day for 15 days in different weeks during the flowering season. The hourly foraging visits of each insect species were recorded on ten different days for which accessible flowering branches were selected. The data obtained was used to calculate the percentage of foraging visits made by each species per day and also to calculate the percentage of foraging visits of each category of insects in a day. A sample of flowers from ten randomly selected plants was used for each mode of breeding system. The stigmas were pollinated with the pollen of the same flower manually by using a brush; they were bagged for fruit set through manipulated autogamy. The flowers were fine-mesh bagged without hand pollination for fruit set through spontaneous autogamy. The emasculated flowers were hand-pollinated with pollen of a different flower on the same plant; they were bagged and followed for fruit set through geitonogamy. The emasculated flowers were pollinated with pollen of a different individual plant and bagged for fruit set through xenogamy. All these modes of pollination were followed for one month to calculate the percentage of fruit set in each mode. A large sample of flowers on fifty inflorescence selected at random were tagged prior to anthesis and followed for fruit and seed set rates in open-pollinations. Fruit maturation period, fruit dehiscence, seed dispersal, and establishment were observed in detail.

\section{Results}

Wendlandia glabrata is a semi-evergreen tree species with scattered distribution in the rocky areas of hill slopes of the Eastern Ghats. The leaves are glabrous and elliptic-lanceolate borne opposite to each other. Flowering occurs from the third week of February to the third week of March at a population level but individual plants flower for three weeks only (Fig. 1). Leaf flushing occurs during the rainy season. Flowering is almost synchronous in all individuals. The inflorescences are hairless, terminal, dense paniculate-cymes and are quite distinct against the foliage. Each inflorescence is $10.8 \pm 2.5 \mathrm{~cm}$ long and produces 285.96 \pm 36.7 flowers within a week (Fig. 2A, B). The flowers are small, white, 9-10 $\mathrm{mm}$ long, narrowly tubular, $4 \mathrm{~mm}$ wide at corolla throat, odourless, regular and bisexual. The calyx is small, light green, basally fused and terminally 5-lobed; it is persistent and transforms into a fruiting calyx after fertilization. The corolla is tubular and 5-lobed, $8 \mathrm{~mm}$ long, white, and conceals nectar. The stamens are five, epipetalous and placed at the throat of the corolla; the anthers are light green, dithecous, dorsi-fixed to short filament, and situated at the height of the fused stigmatic lobes. The ovary is well seated in the calyx, bicarpellary, syncarpous with $87.5 \pm 4.0$ ovules per ovary on axile placentation; the style is erect and terminated with a spathulate, wet, bifid green coloured stigma.

The flowers open at sunrise (06:00-07:00 h). The petals unfold exposing the stigma and stamens beyond the length of the corolla tube. The stamens are protandrous and anther dehiscence occurs during the mature bud stage by longitudinal slits. They gradually bend downwards and move away from the stigmatic lobes following the downward folding of the corolla lobes. During anthesis, the pollen deposition occurs accurately on the outer side of the fused stigma (Fig. 3A-C). A flower produces an average number of $42,327 \pm 126$ pollen grains. The pollen grains are monads, tricolporate, reticulate, circular, powdery, and $18.2 \mu \mathrm{m}$ in size. Pollen viability tests indicated that the grains are viable for two days, the viability rate is the highest in day 1 flowers $(100-76.6 \%)$ and the least in day 2 flowers (27.13-1.8\%) (Table 1). The pollen-ovule ratio is $484: 1$. The stigmatic lobes remain fused after anthesis for about ten hours after which they unfold showing receptivity which ceases by the end of the second day. The receptive phase of the stigma is indicated by its green colour with 
a loss of receptivity indicated by a brown colour after which it shrivels and wilts. The receptive area is only on the inner surface of the stigmatic lobes as determined by a hydrogen peroxide test. The flowers are nectariferous but how much nectar is actually produced by individual flowers could not be measured due to the presence of nectar feeding thrips inside the flower prior to anthesis. Their presence in buds is an indication that they use the flowers as breeding and feeding sites; they also consume pollen. Individual buds/flowers contained 5-7 thrips. In newly open flowers, the nectar is recorded in traces or in minute quantity which is secreted by the nectary around the base of the ovary. The nectar sugar concentration is 23-27\% and consists of glucose, fructose and sucrose with the last as predominant. The nectar also produces five essential amino acids, namely arginine, histidine, lysine, threonine and tryptophan, and nine non-essential amino acids, namely, alanine, amino-butyric acid, cysteine, glutamic acid, glysine, hydroxyproline, proline, serine and tyrosine. The flowers remain in place for four days and fall off subsequently.

Table 1: Results of in vitro pollen viability in Wendlandia glabrata on days one and two.

\begin{tabular}{cccc}
\hline $\begin{array}{c}\text { Time } \\
\text { (h) }\end{array}$ & $\begin{array}{c}\text { No. of } \\
\text { pollen } \\
\text { grains } \\
\text { observed }\end{array}$ & $\begin{array}{c}\text { No. of } \\
\text { pollen } \\
\text { grains } \\
\text { germinated }\end{array}$ & $\begin{array}{c}\text { Pollen } \\
\text { germination } \\
(\%)\end{array}$ \\
\hline $08: 00$ & 132 & 132 & 100 \\
\hline $10: 00$ & 102 & 102 & 100 \\
\hline $12: 00$ & 86 & 80 & 93.02 \\
\hline $14: 00$ & 115 & 102 & 88.6 \\
\hline $16: 00$ & 91 & 75 & 82.4 \\
\hline $18: 00$ & 150 & 115 & 76.6 \\
\hline $08: 00$ & 129 & 35 & 27.13 \\
\hline $10: 00$ & 116 & 18 & 15.5 \\
\hline $12: 00$ & 125 & 6 & 4.8 \\
\hline $14: 00$ & 106 & 2 & 1.8 \\
\hline $16: 00$ & 95 & 0 & 0 \\
\hline $18: 00$ & 49 & 0 & 0 \\
\hline
\end{tabular}

Hand-pollination tests revealed that the plant breeds through geitonogamy and xenogamy only. In geitonogamy, the fruit set is $30 \%$ while seed set is $42 \%$. In xenogamy, the fruit set is $84 \%$ while seed set is $80 \%$. Natural fruit set is $19 \%$ and seed set $62 \%$ (Table 2). These results indicated that the breeding systems are essentially vector-dependent.

The flowers were visited during the day by honey bees, flies and butterflies. The honey bees approached the flowers in an upright position and landed on the inflorescence/flower top for forage collection. The length of the corolla tube is in excess of the tongue length of honey bees and also the corolla tube is narrow. The tongue length is $3.87 \pm 0.3 \mathrm{~mm}$ in Apis dorsata, $3.07 \pm 0.3 \mathrm{~mm}$ in $A$. cerana, $1.93 \pm 0.1$ $\mathrm{mm}$ in A. florea, and $0.98 \pm 0.1 \mathrm{~mm}$ in Trigona iridipennis. Due to mismatch of their tongue length with the corolla tube length, they collected only pollen from the dehisced anthers situated at the corolla throat. All of these bees were consistent foragers throughout the flowering season but their activity showed two peaks, one during forenoon and the other during afternoon. There was a slowdown in foraging visits around mid-day when temperature was at its maximum. They had contact with the stigma while collecting pollen from fresh and aged flowers. Body washing of honey bees collected from the flowers showed that they carry huge number of pollen grains (excluding pollen loads); $2901 \pm 27.9$ in case of A. dorsata, $2012 \pm 20.1$ for A. cerana, 1961 \pm 36.7 for A. florea, and $802 \pm 121.7$ in case of T. iridipennis (Table 3). Flies and butterflies were not consistent foragers throughout the flowering season; butterflies were only occasional in their flower visits. Both are nectar foragers. Flies attempted to collect nectar but their short tongue length $(4.1 \pm 0.7 \mathrm{~mm})$ prevented them from reaching the flower base to collect nectar; in such attempts, their tongue and forehead contact the stigma and pollen pollination occurs. Their foraging visits increased gradually towards noon and gradually decreased from then onwards towards the evening. Butterflies, with their proboscis in excess of the length of corolla tube, successfully collected nectar and in so doing, they contacted the stigma and pollen with their proboscis and forehead. Their foraging activity did not show any definite pattern as they were observed collecting nectar throughout the day. Body washings of proboscis and forehead of butterflies showed that they carry pollen grains ranging from 68-328 (Table 3). All these three categories of insects, whether regular or occasional foraging visitors, were found to be effecting pollination in day 2 flowers only since day 1 flowers were functionally staminate due to non-receptivity of stigma and day 3 and day 4 flowers had lost stigma receptivity. Simultaneous presence of swarms of honey bees on the same plant was found to force them 
to visit other flowering individuals to collect more pollen and such a foraging behavior was considered to be affecting both geitonogamy and xenogamy in day 2 flowers. The clustered state of flowers provides comfortable landing place for the foragers and enables them to probe several flowers in quick succession during each visit. Such floral arrangement and massive flowering was advantageous for the foragers in terms of reducing the search time and also energy expenditure. The data of foraging visits made during the day time by all three groups of insects showed that honey bees made $64 \%$ (Fig. 4), flies $17 \%$ (Fig. 5) and butterflies $20 \%$ (Fig. 6) of the total visits. The study indicated that honey bees were consistent and important pollinators although they were unable to extract nectar, while the other two groups as supplement pollinators.

Table 2: Results of breeding systems in Wendlandia glabrata

\begin{tabular}{lccc}
\hline $\begin{array}{l}\text { Breeding } \\
\text { system }\end{array}$ & $\begin{array}{c}\text { No. of flowers } \\
\text { bagged/tagged }\end{array}$ & $\begin{array}{c}\text { Fruit } \\
\text { set } \\
(\%)\end{array}$ & $\begin{array}{c}\text { Seed } \\
\text { set } \\
(\%)\end{array}$ \\
\hline $\begin{array}{l}\text { Autogamy } \\
\text { (un- } \\
\text { manipulated) }\end{array}$ & 70 & 0 & 0 \\
$\begin{array}{l}\text { Autogamy } \\
\text { (manipulated) }\end{array}$ & 50 & 0 & 0 \\
$\begin{array}{l}\text { Geitonogamy } \\
\text { Xenogamy }\end{array}$ & 50 & 30 & 42 \\
$\begin{array}{l}\text { Open } \\
\text { pollination }\end{array}$ & 50 & 84 & 80 \\
\hline
\end{tabular}

Table 3: Record of pollen grains in the body washings of insect foragers on Wendlandia glabrata $(n=10)$

\begin{tabular}{lcc}
\hline \multicolumn{1}{c}{ Insect species } & $\begin{array}{c}\text { Pollen grains recorded on } \\
\text { bee body }\end{array}$ \\
\hline Bees & Range & Mean \pm SD \\
Apis dorsata & $2310-3450$ & $2901 \pm 27.9$ \\
Apis cerana & $1947-2198$ & $2012 \pm 20.1$ \\
Apis florea & $1903-2067$ & $1961 \pm 36.7$ \\
Trigona iridipennis & $658-1031$ & $802 \pm 121.7$ \\
Butterflies & & \\
Catopsilia pyranthe & $121-319$ & $228.1 \pm 64.4$ \\
Delias eucharis & $92-226$ & $160.0 \pm 48.2$ \\
Melanitis leda & $106-302$ & $206.3 \pm 71.3$ \\
Cirrochroa thais thais & $86-292$ & $178.1 \pm 72.6$ \\
Euploea core & $78-241$ & $158.4 \pm 59.8$ \\
Tagaides gana & $90-328$ & $210.4 \pm 84.7$ \\
Pantoporia hordonia & $112-285$ & $187.6 \pm 59.9$ \\
Elymnias hypermnestra & $68-263$ & $168.3 \pm 67.0$ \\
Hasora chromus & $81-234$ & $171.9 \pm 49.7$ \\
Borbo cinnara & $109-281$ & $193.9 \pm 61.4$ \\
\hline
\end{tabular}

The fruit growth and development (Fig. 3D-F) begins immediately after pollination and fertilization. The fruit is small $(2 \mathrm{~mm}$ long and
$3 \mathrm{~mm}$ wide), globose capsule, light green initially and brown when mature; each fruit produces $37-48$ minute seeds ( $1 \mathrm{~mm}$ long). The mature and dry fruits split apart releasing their tiny seeds into the air during the late summer season. Seeds germinate during the rainy season but the continuous growth and development of seedlings (Fig. 3G) to form new plants is related to nutrient content, moisture availability, and the presence of grass and other herbaceous flora. The seedlings perish mostly due to the rocky habitat and associated negative factors. Seedlings recorded in the study site and the surroundings covering $\sim 1 \mathrm{~km}$ were 52 in 2012 and 32 in 2013. But, the seedling establishment rates were $38.4 \%$ in 2012 and $31.2 \%$ in 2013.

\section{Discussion}

Wendlandia glabrata is a tropical semievergreen tree species that blooms during the first part of dry season from mid-February to mid-March. Its allied species, W. tinctoria, is also a tropical semi-evergreen tree species but initiation of flowering occurs at the lag-end of flowering in W. glabrata from mid-March to mid-April. Further, the two tree species do not occupy the same habitat or region (Solomon Raju et al., 2012). The flowers of W. glabrata are hermaphroditic and monomorphic, an uncommon situation in Rubiaceae in which heterostyly is predominant. But, the hermaphroditic flowers are functionally staminate on the first day of anthesis and pistillate on the following day. Such a temporal separation of male and female phases in bisexual flowers has been referred to as temporal dioecism by Cruden (1988). Further, this sexual system has been reported to be a function of highly synchronous flowering pattern by Cruden \& Hermann-Parker (1977). In W. glabrata also, flowering is massive and highly synchronous even at the population level. The temporal dioecism functional in this species appears to have evolved to promote outcrossing but it does not wholly exclude selfing through geitonogamy. In W. tinctoria, hermaphroditic flowers are morphologically and functionally bisexual although flowering is massive and highly synchronous at population level (Solomon Raju et al., 2012).

Puff et al. (1996) reported that Rubiaceae exhibit four types of Secondary Pollen Presentation (SPP) in relation to the pollen 
presenting area and receptive surfaces of the stigma. As a member of this family, Wendlandia glabrata exhibits a third type in which pollen deposition occurs on the outer surface of the fused stigmatic lobes during anthesis and hence self-pollination is totally prevented. Such a floral mechanism disallows interference of self-pollen but geitonogamy is unavoidable due to the overlap between the functional male and female phases in the inflorescence/plant (Bremer \& Eriksson, 2009). The SPP functional in W. glabrata excludes the occurrence of autogamy and it is substantiated by hand-pollination tests in which the flowers did not set fruit. The temporal dioecism, however, enables the plant to fruit through geitonogamy and fruit set by this pollination mode is supported by hand-pollination test. However, fruit and seed set rates are far less when compared to those recorded in xenogamy. Therefore, the plant has a mixed breeding system and also an essentially pollinator dependent mode for fruit and seed set. Further, geitonogamy is an adaptive functional character to enable mature plants to set fruit and seed in isolation of pollinators when other conspecific individuals are totally absent in the area.

Silberbauer-Gottsberger (1972) stated that many tropical Rubiaceae display floral adaptation suited for Lepidoptera: delicately tubular flowers which are bright red or orange and pollinated by butterflies, and in the case of hawk moths or moths a more or less aromaticscented, whitish flower. Cruden et al. (1983) stated that long tubular flowers with concealed nectar tend to have sucrose-rich nectar. These authors also mentioned that the nectar of most butterfly-pollinated flowers fall within the range of $15-25 \%$ sugar concentration. Kingsolver \& Daniel (1979) suggested that the nectar sugar concentrations of 20-25\% optimize the net energy gain for butterflies. In Wendlandia glabrata, diurnal anthesis, the moderately tubular white flowers, concealed sucrose-rich nectar with 23-27\% sugar concentration and the presence of certain essential and non-essential amino acids in the nectar suggest a psychophilous pollination syndrome. Further, it is substantiated by the fact that insects other than butterflies or moths failed to get access to nectar due to their short tongue length when compared to the corolla tube length. Therefore, W. glabrata displays floral adaptation for pollination by butterflies.
Nonetheless, the present study indicates that this species is principally pollinated by pollencollecting short-tongued honey bees (melittophily). Flies are inconsistent foragers which visit the flowers for nectar collection but do not succeed in reaching the deeply seated nectar; in this flower, they pollinate the flowers and lack the discriminatory power to avoid them based on their previous experience with this floral source. Butterflies are also inconsistent nectar foragers although the flowers display perfect adaptations for pollination by them. This situation might be a result of an availability of traces of nectar in individual flowers due to infestation by nectar and pollen feeding thrips. In W. glabrata, only butterflies access nectar but the inadequate nectar would restrain them from visiting the flowers as their visits are not energetically profitable. It appears to be a case of a breakdown of mutualism between butterflies and the plant although the latter still has a highly specialized psychophilous pollination system. Such a breakdown of mutualism has been reported in the psychophilous plant species, Guihaiothamnus acaulis H. S. Lo (Rubiaceae), distributed in China where it is pollinated by hoverflies and halictid bees (Xie et al. 2012). On the contrary, W. tinctoria with a functional psychophilous pollination syndrome in the southern Eastern Ghats is pollinated by a variety of butterflies and also by bees, wasps and flies (Solomon Raju et al., 2012). Similarly, W. uvariifolia with a psychophilous pollination syndrome is pollinated by a large spectrum of pollinators including butterflies, flies and bees (Xie, 2011).

In Wendlandia glabrata, the fruit and seed set rates recorded in open-pollination are attributable mainly to bees and then to flies and butterflies. The pollen robbery by bees (pollen loads in the corbiculae) and the rocky terrain, characterized by a nutrient-deficient environment, contribute to the recorded fruit and seed set rates. The fruits split apart to disperse seeds into the air. As seeds are tiny, light in weight and are dispersed easily in the air, they are adapted for effective dispersal by wind and hence are anemochorous (Howe \& Westley, 1997). Seeds germinate as soon as they fall to the ground but most of the seedlings soon dry up due to the rocky habitat, desiccation linked to erratic rainfall, nonpenetration of sunlight due to over-growth of 
seasonal herbaceous vegetation, and simple space limitation were the individual seed lands. Therefore, pollen robbery by bees, poor nutrient environment, and the poor competitive ability of seedlings of $W$. glabrata all contribute to the small population size and hence its status as a "rare" plant in the northern Eastern Ghats. We recommend that seedlings should be raised in nurseries and then transplanted into natural area to rebuild population of W. glabrata.

\section{Acknowledgements}

The work reported in this paper is a part of the research project no. 38(1293)/11/EMR-II given to the first author by the Council of Scientific \& Industrial Research, New Delhi. The second author is the Research Associate. We thank CSIR for providing financial support.

\section{Literature Cited}

Baker, H. G. and I. Baker, 1973. Amino acids in nectar and their evolutionary significance. Nature (London), 241: 543-545.

Barrett, S. C., 1992. Heterostylous genetic polymorphisms: Model systems for evolutionary analysis. Pp. 1-29. In: Barrett, S. C. H. (ed.). Evolution and Function of Heterostyly, SpringerVerlag, Berlin.

Bir Bahadur, 1968. Heterostyly in Rubiaceae: A Review. The Journal of Osmania University (Science). Golden Jubilee Special, 4(1/2): 207-238.

Bremer, B. and T. Eriksson, 2009. Time tree of Rubiaceae - Phylogeny and dating the family, subfamilies and tribes. International Journal of Plant Science, 170: 766-793.

Consolaro, H., C. S. S. Simone, and P. E. Oliveira, 2011. Breakdown of distyly and pin-monomorphism in Psychotria carthagensis. Plant Species Biology, 26: $24-32$.

Cruden, R. W., 1988. Temporal dioecism: Systematic breadth, associated traits and temporal patterns. Botanical Gazette, 149: 1-15.

Cruden, R. W. and S. Herrmann-Parker, 1977. Temporal dioecism: An alternative to dioecism? Evolution, 31: 863-866.

Cruden, R. W., S. M. Hermann, and S. Peterson, 1983. Plant-pollinator co-evolution. Pp. 80-125. In: Bentley, B. and T. Elias (eds.). The Biology of Nectaries. Columbia University Press, New York, USA.
Dafni, A., P. G. Kevan, and B. C. Husband, 2005. Practical Pollination Biology. Enviroquest Ltd., Cambridge: 590.

De Block, P. and A. Igersheim, 2001. Stigma of the African genera Rutidea and Nichallea (RubiaceaeIxoroideae-Pavetteae): Highly modified receptive surfaces. International Journal of Plant Sciences, 162: $567-578$.

Harborne, J. B., 1973. Phytochemical Methods. Chapman and Hall, London: 225.

Howe, H. F. and L. C. Westley, 1997. Ecology of pollination and seed dispersal. Pp. 262-283. In: Crawley, M. J. (ed.). Plant Ecology. Blackwell Science, Oxford.

Kingsolver, J. G. and T. L. Daniel, 1979. On the mechanics and energetics of nectar feeding in butterflies. Journal of Theoretical Biology, 76: 167179.

Misra, V. N. and P. Bellwood. (eds.) 1985. Recent Advances in Indo-Pacific Prehistory. Oxford and IBH Publishing Co., New Delhi: 564.

Nilsson, L. A., E. Rabakonandrianina, B. Pettersson, and J. Ranaivo, 1990. Ixoroid secondary pollen presentation and pollination by small moths in the Malagasy treelet Ixora platythyrsa (Rubiaceae). Plant Systematics and Evolution, 170: 161-175.

Puff, C., E. Robbrecht, R. Buchner, and P. De Block, 1996. A survey of secondary pollen presentation in the Rubiaceae. Opera Botanica Belgica, 7: 369-402.

Robbrecht, E., 1988. Tropical woody Rubiaceae. Opera Botanica Belgica, 1: 1-271.

Solomon Raju, A. J., K. V. Ramana, and N. Govinda Rao, 2012. Psychophily and anemochory in Wendlandia tinctoria (Roxb.) DC. (Rubiaceae): A dry season blooming tree species in the dry deciduous southern Eastern Ghats forest, Andhra Pradesh, India. Pakistan Journal of Scientific and Industrial Research, Series B. Biological Sciences, 55: $1-9$.

Xie, P.-W., 2011. Systematics of Wendlandia and Guihaiothamnus (Rubiaceae) in China. Unpublished doctoral dissertation. Guangzhou: South China Botanical Garden, Chinese Academy of Sciences.

Xie, P.-W., Z.-L. Luo, and D.-X. Zhang, 2013. Syrphid fly pollination of Guihaiothamnus acaulis (Rubiaceae), a species with "butterfly" flowers. Journal of Systematics and Evolution, 51: 86-93. 


\section{PLATE 4}

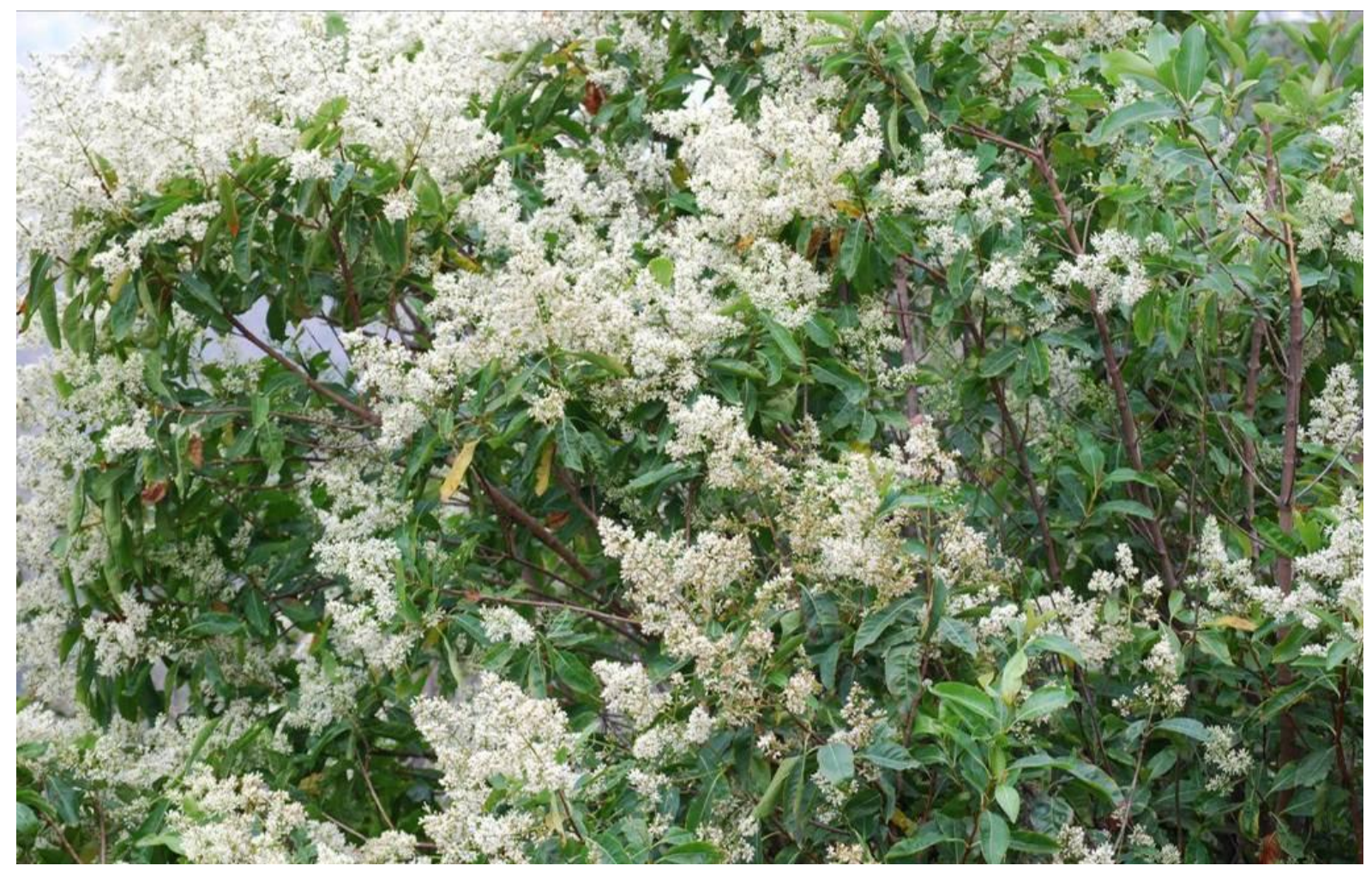

Figure 1: Wendlandia glabrata flowering tree
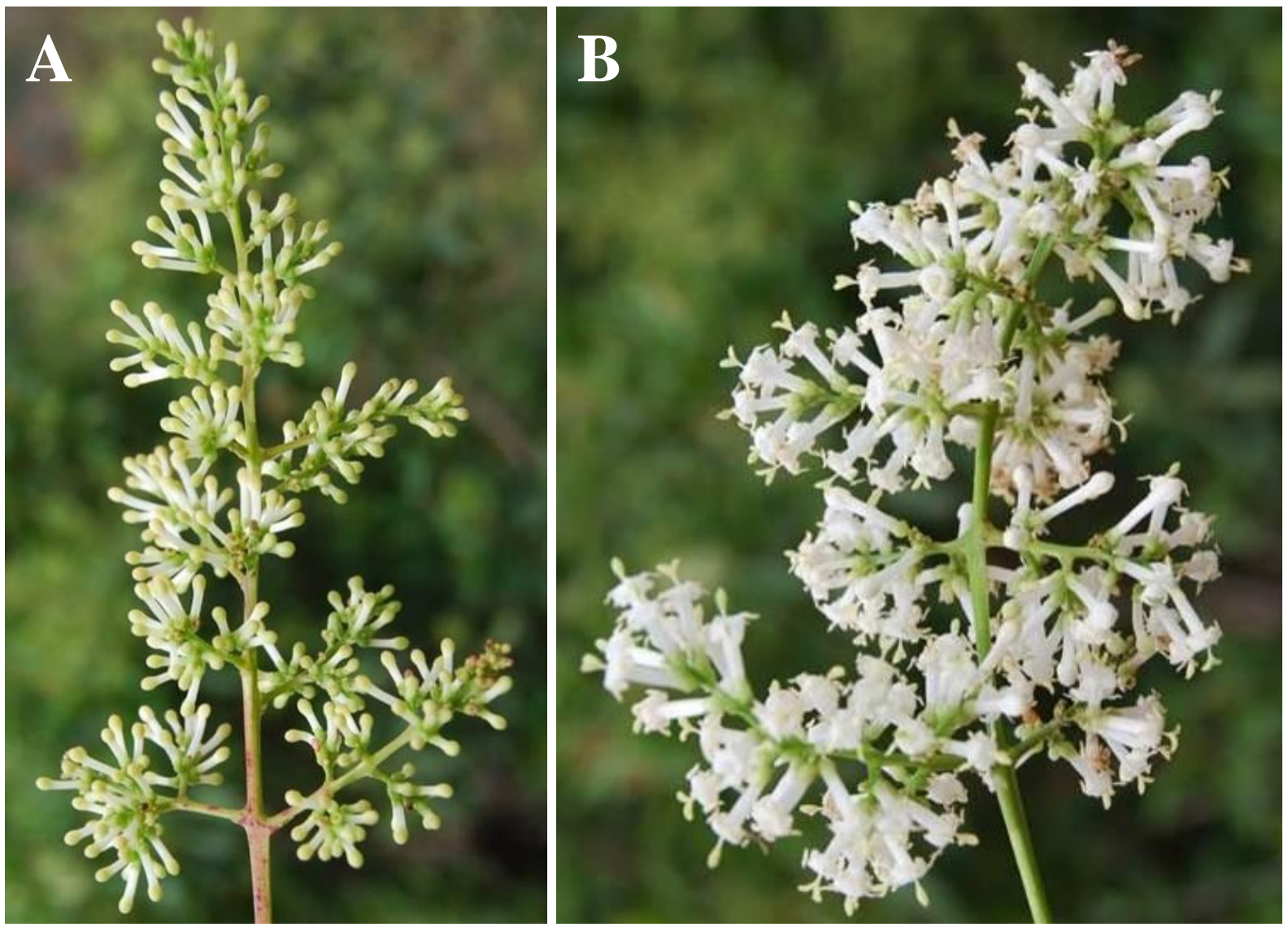

Figure 2: Wendlandia glabrata, A, Inflorescence; B, Flowering inflorescence. 


\section{PLATE 5}
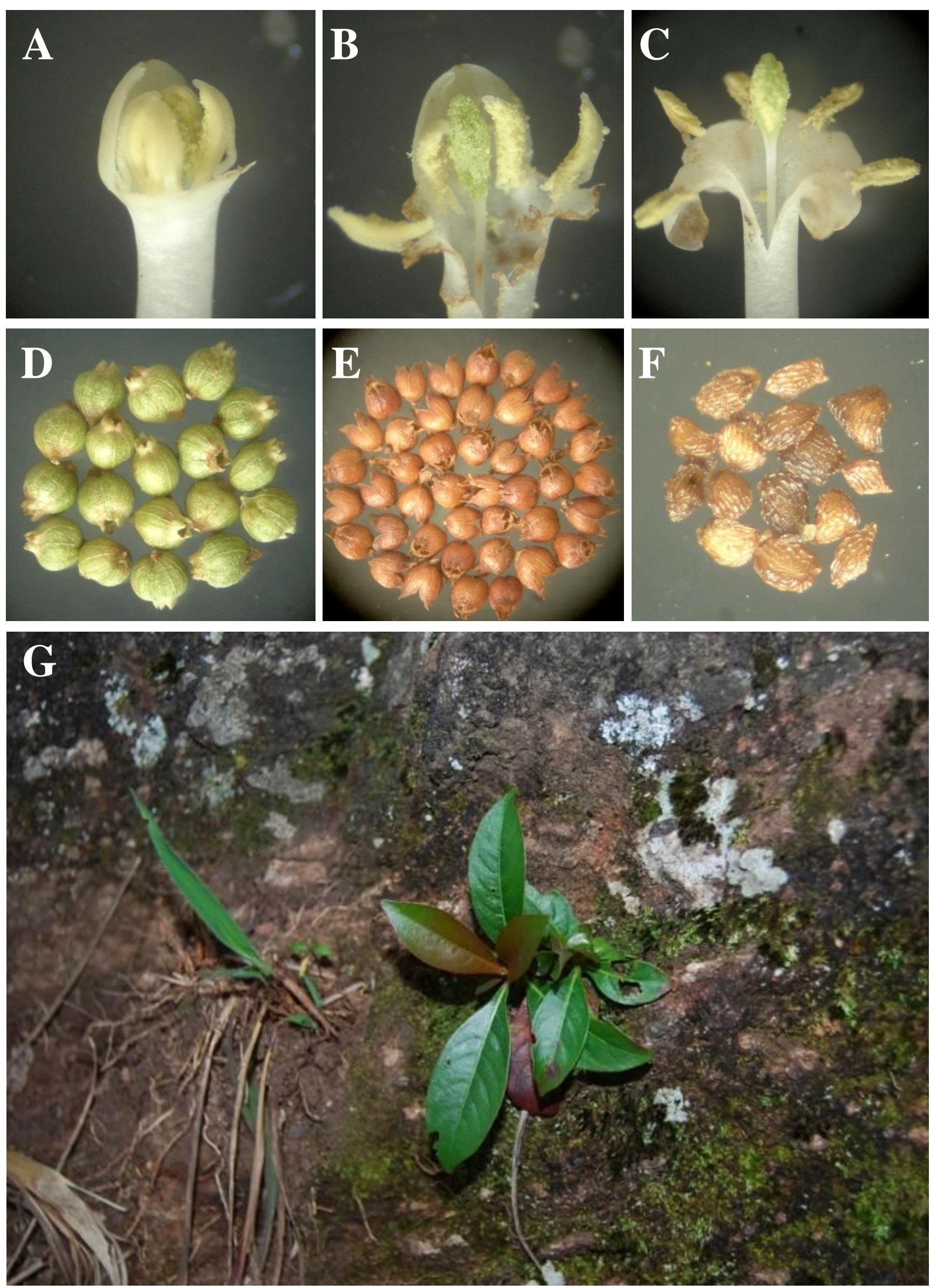

Figure 3: Wendlandia glabrata, A, Anther dehiscence during mature bud stage; B \& C, Stigma outside dusted with self- pollen during anthesis; D, Maturing fruits; E, Mature and dry fruits; F, Seeds; G, Seedling 


\section{PLATE 6}

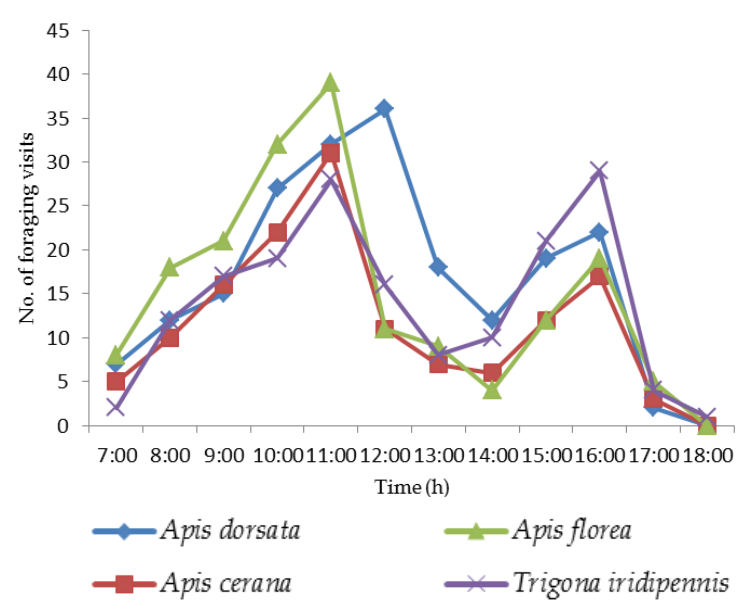

Figure 4: Hourly foraging activity of honey bees on Wendlandia glabrata

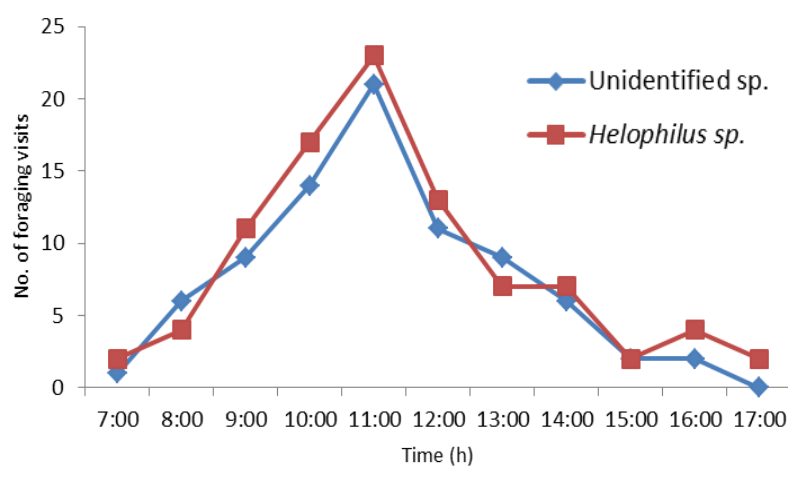

Figure 5: Hourly foraging activity of flies on Wendlndia glabrata

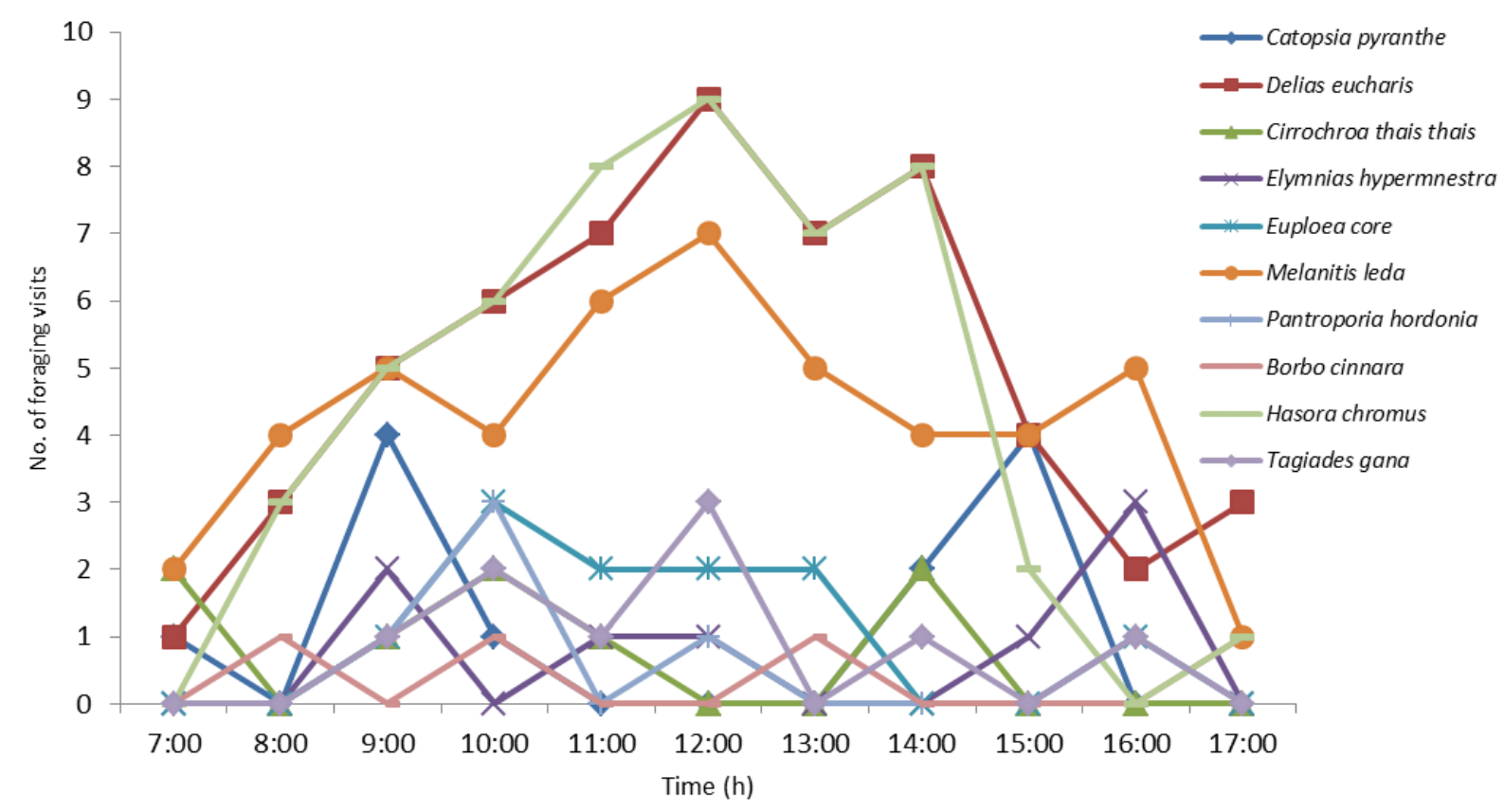

Figure 6: Hourly foraging activity of butterflies on Wendlandia glabrata 